\title{
Training Of Run Star For Agility Volleyball Athlete Junior High School 2 Denpasar
}

\author{
I Gusti Putu Ngurah Adi Santika'), I Putu Gede Adiatmika ${ }^{2)}$, Maryoto \\ Subekti ${ }^{3)}$ \\ ${ }^{1}$ Program Studi Doktor Ilmu Kedokteran Fakultas Kedokteran, \\ ${ }^{2}$ Program Studi Magister Ergonomi-Fisiologi Kerja Fakultas Pascasarjana, \\ ${ }^{3}$ Program Studi Pedidikan Jasmani Kesehatan dan Rekreasi FKIP, \\ 1,2 Universitas Udayana \\ ${ }^{3}$ Universitas PGRI Mahadewa Indonesia \\ Email : ${ }^{1}$ ngurahadisantika@gmail.com, ${ }^{2}$ ipgadiatmika@ unud.ac.id, ${ }^{3}$ maryotosubekti9@gmail.com
}

\begin{abstract}
Based on observations made both in the form of observing the game and measuring the physical components, it was found that the volleyball extracurricular participants at Junior Hight School Negeri 2 Denpasar still experienced problems in changing positions. Changes in positions made by players tend to be slow in responding to the arrival of the ball so that the ball that should have been well anticipated becomes points for the opponent. The purpose of this study was to determine the effect of star running training on body agility. This research is an experimental study with experimental research design randomize pre and post test group design. The total number of samples in this study amounted to 26 people, divided into treatment and control groups. Based on the paired $t$-test, it was found that the mean difference of increasing body agility in the treatment group was 2.08 seconds with a value $(p<0.05)$. From the discussion, it was found that star running training increased the body agility of volleyball athletes at SMP Negeri 2 Denpasar with an increase of $13.84 \%$ with a value ( $p<0.05$ ).
\end{abstract}

Keywords: Run Star, Agility, Volleyball

\section{Pelatihan Lari Bintang Terhadap Kelincahan Tubuh Atlet Bola Voli SMP Negeri 2 Denpasar ABSTRAK}

Berdasarkan observasi yang dilakukan baik berupa pengamatan permainan dan pengukuran komponen fisik diperoleh bahwa siswa peserta ekstrakurikuler bolavoli SMP Negeri 2 Denpasar masih mengalami kendala pada perpindahan posisi. Perpindahan posisi yang dilakukan pemain cenderung lambat dalam merespon datangnya bola sehingga bola yang harusnya bisa diantisipasi dengan baik malah menjadi poin untuk lawan. Tujuan dari penelitian ini adalah untuk mengetahui pengaruh yang dihasilkan dari latihan lari bintang terhadap kelincahan tubuh. Penelitian ini adalah penelitian eksperimental dengan design penelitian Eksperimental Randomize Pre and Post Test Group Design. Jumlah sampel keseluruhan dalam penelitian ini berjumlah 26 orang yang terbagi atas kelompok perlakuan dan kontrol. Berdasarkan uji t-paired diperoleh selisih rerata peningkatan kelincahan tubuh pada kelompok perlakuan 2,08 detik dengan nilai $(\mathrm{p}<0,05)$. Dari pembahasan diperoleh hasil bahwa pelatihan lari bintang meningkatkan kelincahan tubuh atlet bolavoli SMP Negeri 2 Denpasar dengan persentase peningkatan 13,84\% dengan nilai $(p<0,05)$. Berdasarkan pembahsan di atas disimpulkan bahwa pelatihan lari bintang dapat meningkatkan kelincahan tubuh atlet bola voli SMP Negeri 2 Denpasar.

Kata Kunci: Lari Bintang, Kelincahan, Bola voli

Info Artikel

Dikirim

Diterima

: 2 Oktober 2020

: 4 November 2020

Dipublikasikan : 12 November 2020
(C) 2020 IKIP BUDI UTOMO MALANG

P-ISSN 2613-9421

E-ISSN 2654-8003

$\bowtie$ Alamat korespondensi: ngurahadisantika@gmail.com

Universitas Udayana, J1. Raya Kampus Unud Jimbaran, Kec. Kuta Sel., Kabupaten Badung, Bali 80361, Indonesia 
I Gusti Putu Ngurah Adi Santika ${ }^{1)}$, I Putu Gede Adiatmika ${ }^{2)}$, Maryoto Subekti ${ }^{3)}$. Jp.jok (Jurnal Pendidikan. Jasmani,

\section{PENDAHULUAN}

Olahraga merupakan proses sistematik yang berupa segala kegiatan atau usaha yang dapat mendorong mengembangkan dan membina potensi-potensi jasmaniah dan rohaniah seseorang (Santika, 2015). Olahraga merupakan bagian dari aktivitas sehari-hari manusia yang berguna untuk membentuk jasmani dan rohani yang sehat (Candrawati, 2018). Olahraga merupakan hal yang wajib dilakukan oleh seseorang dalam menjaga kondisi tubuh agar terjaga dengan baik dan kondusif (Santika, 2016). Terkait dengan pemeliharaan kondisi fisik, kita sebagai manusia wajib melakukan olahraga sesuai dengan takaran yang kita inginkan.

Olahraga terdiri atas olahraga pendidikan, olahraga kesehatan, olahraga rekreasi dan olahraga prestasi (Giriwijoyo, 2009). Olahraga prestasi adalah olahraga yang membina dan mengembangkan olahragawan secara terencana, berjenjang dan berkelanjutan (Jamalong, 2014). Dengan pembinaan yang baik maka akan dihasilkan atlet yang baik pula. Pembinaan memiliki cakupan yang luas, seperti yang dijelaskan sebelumnya bahwa semua harus terencana. Terencana adalah kita sebagai pelatih wajib menentukan proporsi yang baik dalam membentuk atlet menuju prestasi. Berjenjang sudah pasti mulai dari jenjang terbawah menuju jenjang atas. Kita harus memperkenalkan olahraga sejak dini kepada anak didik dari tingkat SD sampai Mahasiswa. Berkelanjutan memiliki peran penting khususnya seperti contoh bahwa jenjang olahraga tingkat mahasiswa bukanlah tingkat akhir, dalam artian jangan karena kita sudah tamat dari bangku perkuliahan kita langsung stop untuk olahraga. lebih daripada itu kita harus berlanjut dengan tetap melaksanakan olahraga sesuai dengan batasan kita (sesuai dengan umur).

Olahraga bola voli merupakan salah satu cabang olahraga yang memasyarakat di Indonesia (Ismoko \& Sukoco, 2013). Ini terbukti hampir di seluruh pelosok Indonesia mengaplikasikan olahraga bola voli dalam kehidupannya sehari-hari tanpa terkecuali di Pulau Bali. Di Bali olahraga bola voli menjadi sentral aktifnya pelaksanaan olahraga prestasi. Ini tiada lain karena hampir pada lapisan bawah yaitu tingkat Pekan Olahraga Desa (PORDES), olahraga bola voli selalu menjadi prioritas masyarakat. Dengan sumber pemain 
wilayah atau yang kita kenal dengan banjar terdiri dari anak-anak dan orang dewasa. Semuanya berbaur dalam sebuah tim bola voli banjar.

Selain memasyarakat, olahraga bola voli adalah olahraga yang unik. Bola voli adalah olahraga yang unik karena olahraga satu-satunya yang tidak ada kontak fisik antar tim tandingnya (Nielsen \&Yde, 1995). Banyak faktor yang menyebabkan olahraga ini diminati masyarakat, entah apapun alasannya yang jelas olahraga bola voli memang memiliki eksistensi yang tinggi di kancah olahraga Indonesia.

Prestasi yang maksimal dari tim bola voli akan diraih dengan banyak faktor salah satunya adalah kondisi fisik pemain. Kemampuan biomotorik kelincahan dan daya ledak merupakan hal yang penting dalam olahraga bola voli (Mili, Grgantov, \& Kati, 2012). Hal ini terkait dengan perpindahan posisi pemain dalam menghalau bola serta gerak tipu smash yang mengharuskan perpindahan positioning pemain harus berjalan dengan baik. Hal itu membuat pemain bola voli harus memiliki modal dasar berupa kelincahan tubuh yang maksimal.

Kelincahan tubuh merupakan kemampuan tubuh untuk melakukan perubahan arah secara cepat (Santika, 2017). Arah yang dimaksud dalam hal ini adalah depan belakang, kanan dan kiri. Kelincahan merupakan kemampuan tubuh untuk mengubah arah gerakan secara mendadak dalam kecepatan yang tinggi (Adiatmika \& Santika, 2016). Begitu pentingnya kelincahan dalam olahraga bola voli membuat pelatih harus mempersiapkan program yang baik agar atlet memiliki kelincahan yang maksimal.

SMP Negeri 2 Denpasar merupakan sekolah yang eksis dalam pelaksanaan Pekan Olahraga Pelajar (PORJAR). Salah satu cabang olahraga yang diikut sertakan dalam event tersebut adalah bola voli. Eksistensi bola voli di SMP Negeri 2 Denpasar terlihat dari minat siswa yang mengikuti ekstrakurikuler bolavoli. Dari 50 orang jumlah peserta ekstrakurikuler bola voli, keseluruhannya diikuti oleh siswa putra saja. Ini juga menjadi faktor kenapa SMP Negeri 2 Denpasar hanya mengirimkan tim putra saja pada ajang PORJAR.

Prestasi SMP Negeri 2 Denpasar pada event PORJAR untuk cabang olahraga bola voli belumlah maksimal. Berdasarkan observasi yang dilakukan baik berupa pengamatan permainan dan pengukuran komponen fisik diperoleh 
I Gusti Putu Ngurah Adi Santika ${ }^{1)}$, I Putu Gede Adiatmika ${ }^{2)}$, Maryoto Subekti ${ }^{3)}$. Jp.jok (Jurnal Pendidikan. Jasmani,

bahwa siswa peserta ekstrakurikuler bolavoli SMP Negeri 2 Denpasar masih mengalami kendala pada perpindahan posisi. Perpindahan posisi yang dilakukan pemain cenderung lambat dalam merespon datangnya bola sehingga bola yang harusnya bisa diantisipasi dengan baik malah menjadi poin untuk lawan.

Setelah dilakukan pengukuran komponen fisik pada bulan Maret 2018 yang berkaitan dengan perpindahan posisi pemain yang dalam hal ini kelincahan tubuh dalam memindahkan posisi dari titik satu ke titik yang lainnya, diperoleh bahwa kelincahan tubuh peserta ekstrakurikuler bola voli SMP Negeri 2 Denpasar masih berada pada kategori kurang (Santika, 2018). Hal ini tentunya menjadi masalah bagi cabang olahraga bola voli di SMP Negeri 2 Denpasar. Supaya SMP Negeri 2 Denpasar tidak sebagai tim penghibur semata, maka komponen kelincahan wajib untuk ditingkatkan levelnya.

Kita telah banyak mengetahui metode pelatihan yang dipergunakan untuk meningkatkan kelincahan tubuh diantaranya : 1) memberikan latihan lari amplop dalam meningkatkan kelincahan tubuh (Pratama, Parwata \& Santika, 2016), 2) memberikan latihan double dot drill dalam meningkatkan kelincahan tubuh (Suryanata, Yasa \& Santika, 2018) dan 3) pemberian pelatihan dengan metode zig-zag run dalam meningkatkan kelincahan tubuh (Ahmad, 2018). dari semua metode tersebut masih memiliki sudut arah gerakan yang tidak mewakili konsep arah kelincahan yaitu depan, belakang, kanan dan kiri.

Berkaitan dengan permasalahan yang ada di SMP Negeri 2 Denpasar khususnya dalam hal kurangnya kelincahan tubuh peserta ekstrakurikuler bola voli serta masih monotonnya metode pelatihan dalam meningkatkan kelincahan tubuh, maka peneliti membuat judul Pelatihan Lari Bintang Terhadap Kelincahan Tubuh Atlet Bola voli SMP Negeri 2 Denpasar.

Dari latar belakang di atas dihasilkan rumusan masalah yaitu apakah ada pengaruh pelatihan lari bintang dalam meningkatkan kelincahan tubuh atlet bola voli SMP Negeri 2 Denpasar, terkait dengan rumusan masalah tersebut, tujuan yang ingin dicapai dalam penelitian ini adalah untuk mengetahui seberapa besar pengaruh yang diberikan dari latihan lari bintang dalam meningkatkan kelincahan tubuh atlet bola voli SMP Negeri 2 Denpasar. Adapun hipotesis yang diajukan 
dalam penelitian ini adalah ada pengaruh pelatihan lari bintang terhadap kelincahan tubuh atlet bola voli SMP Negeri 2 Denpasar.

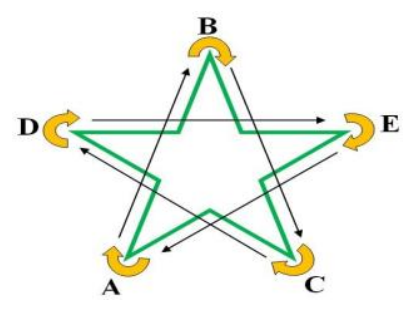

Gambar 1. Pola Lari Bintang (Santika, 2018)

Lari bintang merupakan pengembangan dari metode yang telah ada. Mencoba dengan konsep baru berdasarkan konsep arah kelincahan maka terbentuklah lari pola bintang. Sering salah tafsir terkait dengan jarak tempuh dari titik A dan B dan seterusnya. Apabila jaraknya kita perpanjang dari titik A dan titik B maka yang akan dilatih adalah daya tahan. Sebaliknya apabila jarak dari titik A dan titik B kita perpendek maka yang dilatih adalah kelincahan.

Kelincahan adalah kemampuan tubuh merubah arah secepat mungkin dengan jarak total raihan adalah $40 \mathrm{~m}$ (Nala, 2016). Pada gambar 2 jarak antara dari titik A ke B dan seterusnya adalah 4 meter. Sampel penelitian dalam pelaksanaan pelatihan ini akan melakukan 2 kali putaran dari titik A sampai kembali ke titik A dengan jarak total $40 \mathrm{~m}$. Dengan demikian jarak tempuh latihan kelincahan terpenuhi.

Berdasarkan penelitian sebelumnya dengan mempergunakan metode zig-zag run (Ahmad, 2018). Didapatkan hasil peningkatan sebesar 0,91 detik dihitung dari selisih rerata pretest (14,02 detik) menjadi post test (13,11 detik). Apabila dilihat dari hasil latihan lari bintang diperoleh hasil peningkatan sebesar 2,08 detik dihitung dari selisih rerata pretest $(15,02$ detik) menjadi post test $(12,94$ detik).

Kelincahan merupakan kemampuan tubuh merubah arah secepat mungkin (Nala, 2016). Sesuai dengan pendapat tersebut bahwa kelincahan sejatinya melakukan perubahan arah gerak tubuh ke segala arah. Pelatihan zig-zag run hanya memakai arah kiri dan kanan saja sedangkan pada lari bintang arahnya lebih variatif yaitu kanan, kiri, depan dan belakang. 


\section{METODE}

Penelitian ini adalah penelitian eksperimental dengan design penelitian Eksperimental Randomize Pre and Post Test Group Design (Sugiyono, 2013).

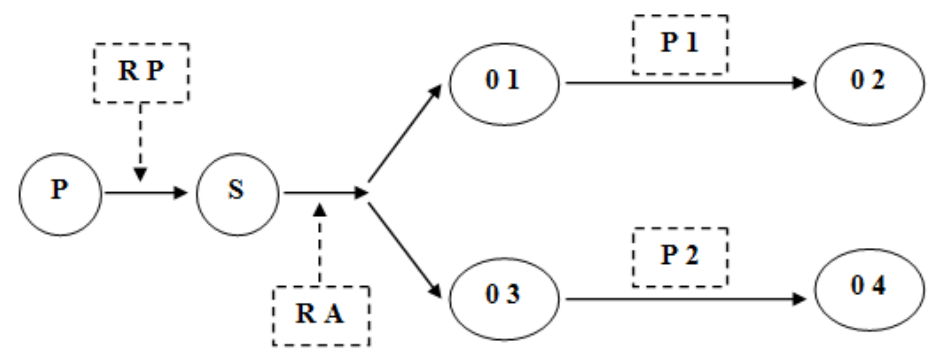

Gambar 2. Rancangan Penelitian

Keterangan :

P : Populasi

RP : Rumus Pocock

S : Sampel

RA : Random Alokasi

O1 : Pre test Kelompok Kontrol (Latihan Zig-Zag Run)

O2 : Post test Kelompok Kontrol (Latihan Zig-Zag Run))

O3 : Pre test Kelompok Perlakuan (Latihan Lari Bintang)

O4 : Post test Kelompok Kontrol (Latihan Lari Bintang)

P1 : Pelatihan Kelompok Kontrol (Latihan Zig-Zag Run selama 6 minggu)

P2 : Pelatihan Kelompok Perlakuan (Latihan Lari Bintang selama 6 minggu)

Penelitian ini dilaksanakan dari tanggal 8 April-19 Mei 2018 pada pukul 16.00 WITA. Pelatihan ini dilaksanakan selama 6 minggu dengan frekuensi pelatihan ini adalah 4 kali seminggu yaitu pada hari Selasa, Kamis, Sabtu dan Minggu. Populasi penelitian adalah siswa peserta ekstrakurikuler bola voli SMP Negeri 2 Denpasar yang berjumlah 50 orang. Dari 50 orang populasi diperoleh jumlah sampel sebesar 11 orang per kelompok untuk menghindari data sampel drop out/keluar, maka jumlah sampel ditambah 2 orang per kelompok sehingga jumlah sampel per kelompok menjadi 13 orang. Mengingat penelitian ini adalah eksperimen maka terdapat 2 kelompok dalam penelitian ini sehingga total sampel diperoleh 26 orang untuk dua kelompok yang terbagi dalam kelompok perlakuan 
dan kelompok kontrol. Penentuan sampel mempergunakan rumus Pocock dimana data sampel didasarkan atas data penelitian pendahuluan (Pocock, 2008).

Populasi penelitian yang berjumlah 50 orang diperoleh dari kriteria inklusi penelitian diantaranya : 1) jenis kelamin laki-laki, 2) berstatus sebagai peserta ekstrakurikuler bola voli SMP Negeri 2 Denpasar, 3) bersedia mengikuti latihan. Untuk jumlah sampel penelitian yang berjumlah 11 orang diperoleh dengan mempergunakan rumus Pocock. Rumus Pocock adalah rumus penentuan sampel yang dipergunakan oleh sport medicine dalam menentukan sampel yang berkaitan dengan latihan. Penggunaan rumus Pocock tidaklah sembarangan, berbeda dengan rumus sampel yang lainnya. Untuk menentukan sampel kita harus melakukan penelitian pendahuluan terlebih dahulu.

$$
\mathrm{n}=\frac{2\left(\sigma^{2}\right)}{(\mu 2-\mu 1)^{2}} f(\alpha, \beta)
$$

Gambar 3. Rumus Pocock (Pocock, 2008)

Keterangan :

n : Jumlah Sampel

$\sigma \quad$ : Standar Deviasi

$\mu 2$ : Rerata kelincahan harapan setelah pelatihan

$\mu 1 \quad$ : Rerata kelincahan penelitian pendahuluan

$f(\alpha, \beta) \quad: 10,5$ (Tabel of Value)

Diketahui :

$\begin{array}{ll}\sigma & : 1,85 \\ \mu 2 & : 14,79 \text { detik } \\ \mu 1 & : 17,41 \text { detik } \\ f(\alpha, \beta) & : 10,5\end{array}$

Jawab :

$$
\mathrm{n}=\frac{2\left(\sigma^{2}\right)}{(\mu 2-\mu 1)^{2}} f(\alpha, \beta)
$$


I Gusti Putu Ngurah Adi Santika ${ }^{1)}$, I Putu Gede Adiatmika ${ }^{2)}$, Maryoto Subekti ${ }^{3)}$. Jp.jok (Jurnal Pendidikan. Jasmani,

$\mathrm{n}=\frac{}{(14,79-17,41)^{2}} 10,5$

6,845

$\mathrm{n}=\frac{6,845}{(-2,62)^{2}} 10,5$

$\mathrm{n}=\frac{6,845}{6,8644} 10,5$

$\mathrm{n}=\frac{71,8725}{6,8644}$

$\mathrm{n}=10,5$

Ketentuan dalam Rumus Pocock adalah apabila angka yang dihasilkan memiliki pecahan desimal dari 0,5 ke atas maka dibulatkan menjadi 1, Maka angka 10,5 yang diperoleh dibulatkan menjadi 11. Mengingat penelitian ini adalah penelitian eksperimen yang berlangsung cukup lama yaitu selama 6 minggu, maka peneliti wajib memberikan sampel cadangan untuk menghindari terjadinya drop out seperti : 1) sampel sakit, 2) sampel mengalami cedera saat latihan, 3) sampel mengalami kecelakaan. Hal ini sering terlupakan oleh peneliti, maka dari itu peneliti wajib memberikan sampel cadangan, dengan tujuan agar sampel murni yang kita miliki tetap utuh sampai akhir penelitian. Penelitian cadangan diberikan 20\% dari jumlah sampel yang dihasilkan oleh rumus pocock, sehingga jumlahnya menjadi $(20 \%$ x $11=2,2)$ dibulatkan menjadi 2 . Maka jumlah total sampel per kelompok menjadi $(11+2=13$ orang). Ingat tugas sampel cadangan hanya menjaga keutuhan jumlah sampel murni, sampel cadangan tidak masuk hitungan dalam analisis data.

Adapun analisis data yang dipergunakan dalam penelitian ini diantaranya : 1) analisis deskriptif untuk menganalisis rerata, SB, minimum dan maksimum kelincahan tubuh atlet bola voli SMP Negeri 2 Denpasar, 2) uji normalitas data dengan Shapiro Wilk Test yang bertujuan untuk mengetahui normalitas data kelincahan tubuh pada masing-masing kelompok perlakuan dan kontrol, 3) uji homogenitas dengan Levene's Test bertujuan mencari homogenitas data kelincahan tubuh pada kelompok perlakuan dan kontrol, 4) uji t-paired test dipergunakan menganalisis rerata perubahan hasil kelincahan tubuh antara 
sebelum dan sesudah pelatihan pada masing-masing kelompok dan 5) uji TIndependent Test dipergunakan menganalisis rerata perubahan kelincahan tubuh antar kedua kelompok pre dan post.

\section{HASIL DAN PEMBAHASAN}

Tahap pertama yang dilakukan adalah dengan menguji normalitas dan homogenitas data yang kita miliki agar kita tahu apakah kita akan masuk ke uji parametrik atau non parametrik. Apabila pada uji normalitas nilai p lebih besar dari 0,05 (p>0,05), maka dilanjutkan ke uji parametrik. Sedangkan apabila pada uji normalitas nilai $\mathrm{p}$ lebih kecil dari $0,05(\mathrm{p}<0,05)$, maka proses selanjutnya dilanjutkan ke uji non parametrik. Berikut tabel uji normalitas dan homogenitas data pada masing-masing kelompok :

Tabel 1. Uji Normalitas dan Homogenitas Data

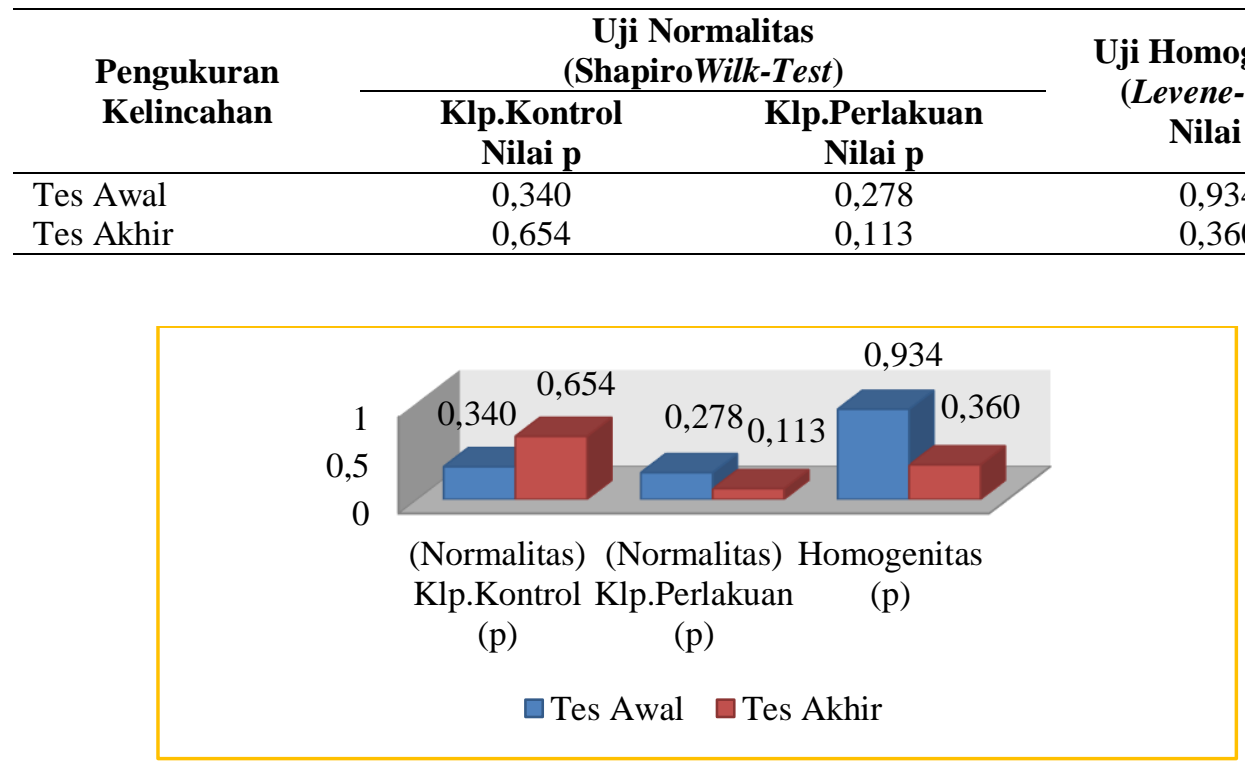

Grafik 1. Uji Normalitas dan Homogenitas Data pada Kelompok Perlakuan dan Kelompok Kontrol Sebelum dan Sesudah Pelatihan

Berdasarkan uji normalitas data diperoleh nilai p pada tes awal kelompok kontrol 0,340 dan pada tes akhir 0,654. Sedangkan pada tes awal kelompok perlakuan diperoleh nilai p 0,278 dan pada tes akhir 0,113. Berdasarkan data tersebut menunjukan bahwa nilai $\mathrm{p}$ lebih besar dari 0,05 ( $\mathrm{p}>0,05)$. Artinya data 
I Gusti Putu Ngurah Adi Santika ${ }^{1)}$, I Putu Gede Adiatmika ${ }^{2)}$, Maryoto Subekti ${ }^{3)}$.Jp.jok (Jurnal Pendidikan. Jasmani,

pada masing-masing kelompok untuk tes awal dan tes akhir berdistribusi normal dan bisa masuk ke tahap berikutnya yaitu uji parametrik.

Uji berikutnya adalah masuk ke dalam uji t-paired test dipergunakan untuk mengetahui seberapa besar dampak pelatihan yang dihasilkan oleh masingmasing kelompok terhadap kelincahan tubuh atlet bola voli SMP Negeri 2 Denpasar. Berikut tabel uji t-paired test pada masing-masing kelompok :

Tabel 2. Uji t-paired test pada Kelompok Perlakuan dan Kontrol

\begin{tabular}{|c|c|c|c|c|c|c|c|c|}
\hline $\begin{array}{l}\text { Pen } \\
\text { Kel }\end{array}$ & $\begin{array}{l}\text { ukuran } \\
\text { lcahan }\end{array}$ & Minimum & Maximal & Mean & SB & Beda & $\mathbf{t}$ & $\mathbf{p}$ \\
\hline \multirow{2}{*}{$\begin{array}{l}\text { Klp. } \\
\text { Kontrol }\end{array}$} & $\begin{array}{l}\text { Tes Awal } \\
\text { (dtk) }\end{array}$ & 13,45 & 16,70 & 15,01 & 1,10 & \multirow{2}{*}{1,13} & \multirow{2}{*}{9,026} & \multirow{2}{*}{0,000} \\
\hline & $\begin{array}{l}\text { Tes Akhir } \\
(\mathrm{dtk})\end{array}$ & 12,95 & 15,03 & 13,88 & 0,64 & & & \\
\hline \multirow{2}{*}{$\begin{array}{l}\text { Klp. } \\
\text { Perlakuan }\end{array}$} & $\begin{array}{l}\text { Tes Awal } \\
\text { (dtk) }\end{array}$ & 13,48 & 16,72 & 15,02 & 1,10 & \multirow{2}{*}{2,08} & \multirow{2}{*}{20,743} & \multirow{2}{*}{0,000} \\
\hline & $\begin{array}{l}\text { Tes Akhir } \\
\text { (dtk) }\end{array}$ & 11,43 & 14,21 & 12,94 & 0,87 & & & \\
\hline
\end{tabular}

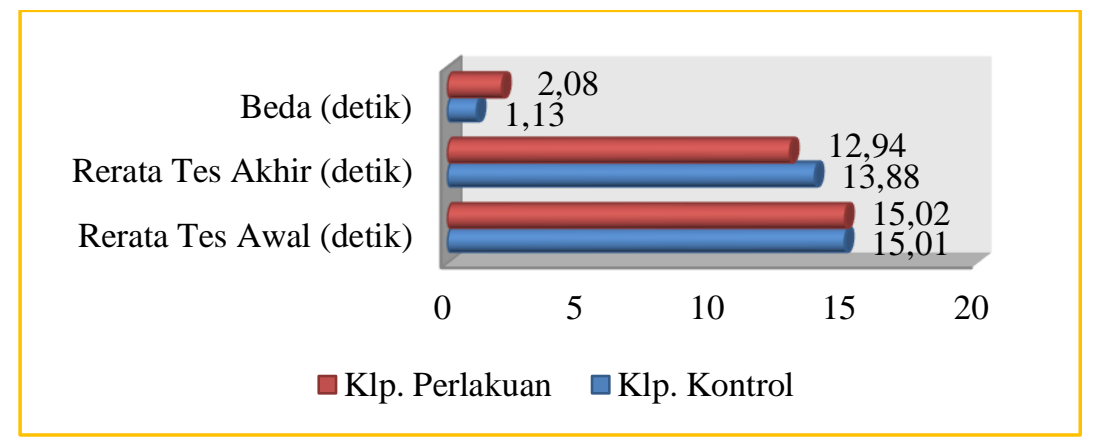

Grafik 2. Uji t-paired test pada Kedua Kelompok

Berdasarkan tabel 2 diperoleh data kelincahan tubuh pada kelompok kontrol dengan rerata tes awal 15,01 $\pm 1,10$ detik dengan rerata tes akhir 13,88 $\pm 0,64$ detik dan beda rerata tes awal dan tes akhir kelompok kontrol sebesar 1,13 detik dengan $(\mathrm{p}<0,05)$. Ini menunjukan ada perbedaan yang bermakna pelatihan yang diberikan pada kelompok pembanding/kontrol (Pelatihan Zig-Zag Run).

Sedangkan pada kelompok perlakuan dengan rerata tes awal 15,02 $\pm 1,10$ detik dengan rerata tes akhir $12,94 \pm 0,87$ detik dan beda rerata tes awal dan tes akhir kelompok perlakuan sebesar 2,08 detik $(\mathrm{p}<0,05)$. Hal ini menunjukan 
terdapat perbedaan yang bermakna pelatihan yang diberikan pada kelompok perlakuan (Pelatihan Lari Bintang).

Apabila kita bandingkan efek pelatihan yang dihasilkan pada kelompok kontrol dan kelompok perlakuan maka akan terlihat pada tabel berikut ini :

Tabel 3. Persentase Efek Pelatihan yang Terjadi pada Kelompok Kontrol dan Kelompok Perlakuan

\begin{tabular}{lcc}
\hline \multicolumn{1}{c}{ Hasil Analisis } & $\begin{array}{c}\text { Kelompok } \\
\text { Kontrol }\end{array}$ & $\begin{array}{c}\text { Kelompok } \\
\text { Perlakuan }\end{array}$ \\
\hline Tes Awal Kelincahan Tubuh (detik) & 15,01 & 15,02 \\
Tes Akhir Kelincahan Tubuh (detik) & 13,88 & 12,94 \\
Selisih Kelincahan Tubuh (detik) & 1,13 & 2,08 \\
Persentase $(\%)$ & 7,52 & 13,84 \\
\hline
\end{tabular}

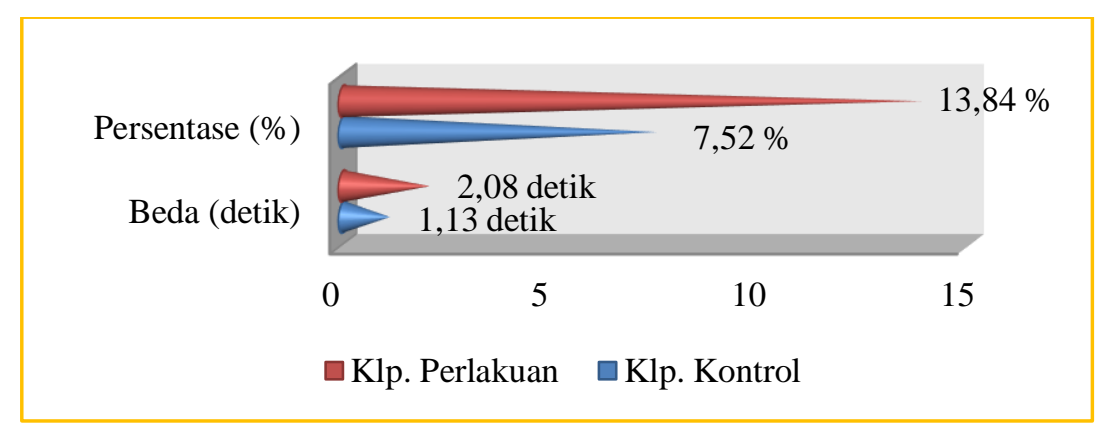

Grafik 3. Grafik Perbedaan Efek Pelatihan pada Kelompok Kontrol dan

Perlakuan serta Persentasenya

Berdasarkan tabel 3 terlihat bahwa perbedaan efek pelatihan yang dihasilkan oleh kelompok kontrol 1,13 detik sedangkan pada kelompok perlakuan 2,08 detik. Persentase peningkatan kelincahan tubuh yang dihasilkan oleh kelompok kontrol 7,52\% sedangkan pada kelompok perlakuan $13,84 \%$.

Setelah tadi kita membahas efek pelatihan pada masing-masing kelompok, sekarang kita akan membahas efek pelatihan antar kelompok. Untuk mengetahui perbedaan efek pelatihan antar kelompok maka kita masuk ke dalam uji tindependent. Adapun tabelnya sebagai berikut : 
Tabel 4. Tabel Uji t-Independent

\begin{tabular}{lllllr}
\hline & Klp. & Mean & t & p & $\begin{array}{r}\text { Beda } \\
\text { Rerata }\end{array}$ \\
\hline \multirow{2}{*}{ Post-test } & Kontrol & $13,88 \pm 0.64$ & 3.331 & 0,001 & 0,94 \\
\cline { 2 - 6 } & Perlakuan & $12,94 \pm 0.87$ & 3.94 &
\end{tabular}

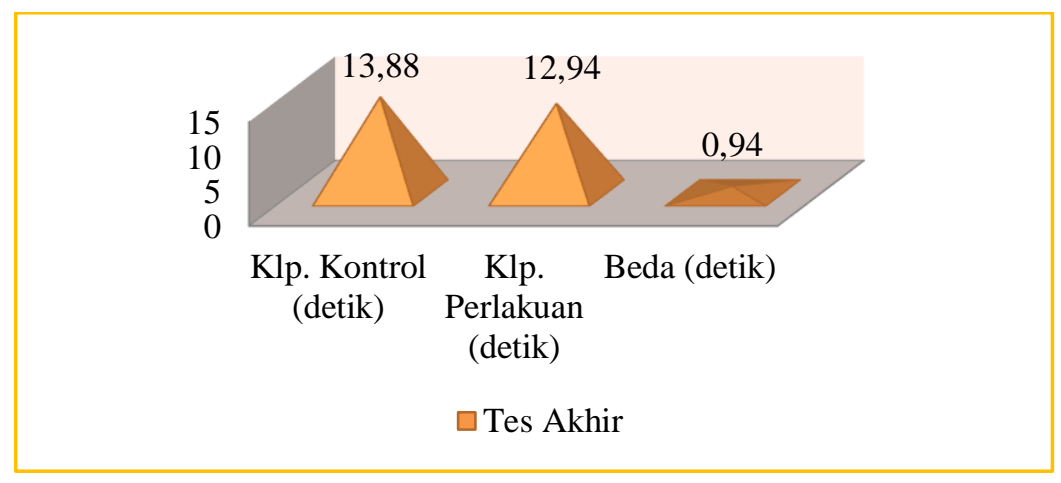

Grafik 4. Uji t-Independent

Berdasarkan tabel 4 diperoleh $(\mathrm{p}<0,05)$ yang berarti bahwa diperoleh perbedaan yang bermakna dari hasil akhir (post-test) pada kedua kelompok.

Berdasarkan penelitian sebelumnya dengan mempergunakan metode zig-zag run (Ahmad, 2018). Didapatkan hasil peningkatan sebesar 0,91 detik dihitung dari selisih rerata pre test $(14,02$ detik) menjadi post test $(13,11$ detik). Apabila dilihat dari hasil latihan lari bintang diperoleh hasil peningkatan sebesar 2,08 detik dihitung dari selisih rerata pre test $(15,02$ detik) menjadi post test $(12,94$ detik).

Kelincahan merupakan kemampuan tubuh merubah arah secepat mungkin (Nala, 2016). Sesuai dengan pendapat tersebut bahwa kelincahan sejatinya melakukan perubahan arah gerak tubuh ke segala arah. Arah tersebut ada kanan, kiri, depan belakang, belum sudut depan kanan dan kiri serta sudut belakang kanan dan kiri. Pelatihan zig-zag run hanya memakai arah kiri dan kanan saja sedangkan pada lari bintang arahnya lebih variatif yaitu kanan, kiri, depan dan belakang. Dengan hal ini membuat kinerja tubuh dalam melakukan adaptasi terhadap pola latihan dengan arah yang bervariatif (5 arah) lebih meningkatkan kelincahan tubuh dari pada mempergunakan dua arah saja. 


\section{SIMPULAN}

Berdasarkan pembahasan diatas, disimpulkan bahwa pelatihan lari bintang dapat meningkatkan kelincahan tubuh atlet bola voli SMP Negeri 2 Denpasar. Sehingga hipotesis yang diajukan yang berbunyi pelatihan lari bintang meningkatkan kelincahan tubuh atlet bola voli SMP Negeri 2 Denpasar diterima.

\section{DAFTAR RUJUKAN}

Adiatmika, I. P. G \& Santika, I. G. P. N. A. (2016). Bahan Ajar Tes dan Pengukuran Olahraga. Denpasar : Udayana University Press

Ahmad, N. (2018). Pengaruh Latihan Zig Zag Run Terhadap Kelincahan Atlet Pencak Silat Tapak Suci Lebong. Journal Physical Education, Health and Recreation, Vol. 2, p. 181. https://doi.org/10.24114/pjkr.v2i2.9589

Candrawati, Y., Sugiyanto, Ilahi, B. R. (2018). Evaluasi Program Pembinaan Prestasi Olahraga Bolavoli pada SMK Negeri di Kota Bengkulu. KINESTETIK : Jurnal Ilmiah Pendidikan Jasmani, 2(1), 44-48. https://ejournal.unib.ac.id/index.php/kinestetik/article/view/9186

Giriwijoyo, H. Y. S. S. (2009). Pengantar Ilmu Faal Olahraga. Bandung : PFOK Universitas Pendidikan Indonesia

Ismoko, Anung Probo; Sukoco, Pamuji. (2013). Pengaruh Metode Latihan dan Koordinasi Terhadap Power Tungkai Atlet Bolavoli Junior Putri. Jurnal Keolahragaan, $\quad 1 \quad$ (1), 1-12. https://journal.uny.ac.id/index.php/jolahraga/article/view/2339

Jamalong, A. (2014). Peningkatan Prestasi Olahraga Nasional Secara Dini Melalui Pusat Pembinaan dan Latihan Pelajar (PPLP) dan Pusat Pembinaan dan Latihan Mahasiswa (PPLM). Jurnal Pendidikan Olah Raga, 3(2), 156-168. https://journal.ikippgriptk.ac.id/index.php/olahraga/article/view/127/125

Mili, Mirjana; Grgantov, Zoran; Kati, Ratko. (2012). Biomotor Status and Kinesiological Education of Girls Aged 10 to 12 Tears-Example : Volleyball. Collegium Antropologicum, 36 (3), 959-966. https://hrcak.srce.hr/90454

Nala. (2016). Prinsip Pelatihan Fisik Olahraga. Denpasar : Udayana University Press

Nielsen, A. B., \& Yde, J. (1995). Prospective Study. 29(3), 200-204.

Pocock, S,J. (2008). Clinical Trial, A Pratical Approach, Cichestes. New York : John Wiley \& Sons

Pratama, Y. S., Parwata, Y., \& Santika, N. A. (2016). Pelatihan Lari Amplop Meningkatkan Kelincahan Siswa Putra Peserta Ekstra Kurikuler Pencak Silat Sma Dwijendra Denpasar Tahun Pelajaran 2015/2016. Jurnal Pendidikan 
Kesehatan Rekreasi, 2(2), 21-25. Retrieved from https://ojs.ikippgribali.ac.id/index.php/jpkr/article/view/190

Santika I Gusti putu ngurah adi. (2015). Hubungan Indeks Masa Tubuh (IMT) Dan Umur Terhadap Daya Tahan Umum (Kardiovaskuler) Mahasiswa Putra Semester II Kelas A Fakultas Pendidikan Olahraga Dan Kesehatan IKIP PGRI Bali Tahun 2014. Jurnal Pendidikan Kesehatan Rekreasi, 1(1), 42-47. https://doi.org/10.1145/3132847.3132886

Santika, I. G. P. N. A. (2016). Pengukuran Tingkat Kadar Lemak Tubuh Melalui Jogging Selama 30 Menit Mahasiswa Putra Semester IV FPOK IKIP PGRI Bali Tahun 2016. Jurnal Pendidikan Kesehatan Rekreasi, 2(1), 89-98. Retrieved from https://ojs.ikippgribali.ac.id/index.php/jpkr/article/view/165 (Original work published June 30, 2016)

Santika, I. G. P. N. A. (2017). Pengukuran Komponen Biomotorik Mahasiswa Putra Semester V Kelas A Fakultas Pendidikan Olahraga Dan Kesehatan IKIP PGRI Bali Tahun 2017. Jurnal Pendidikan Kesehatan Rekreasi, 3(1), 85-92. Retrieved from https://ojs.ikippgribali.ac.id/index.php/jpkr/article/view/221

Santika, I. G. P. N. A. (2018). Pengukuran Komponen Fisik Ekstrakurikuler Bolavoli SMP Negeri 2 Denpasar Tahun 2018. Denpasar : FPOK IKIP PGRI Bali

Santika, I. G. P. N. A. (2018). Pelatihan Lari Bintang Terhadap Kelincahan Tubuh Atlet Bola Voli SMP Negeri 2 Denpasar . Denpasar : FPOK IKIP PGRI Bali.

Sugiyono. (2013). Metode Penelitian Kuantitatif, Kualitatif dan R\&D. Bandung : ALFABETA

Suryanata, I., Yasa, I. M., \& Santika, I. N. A. (2018). Pelatihan Double Dot Drill 2 Repetisi 3 Set Meningkatkan Kelincahan Siswa Putra Peserta Ekstra Kurikuler Pencak Silat SMP Negeri 1 Kuta Selatan Tahun Pelajaran 2016/2017. Jurnal Pendidikan Kesehatan Rekreasi, 4(1), 33-38. Retrieved from https://ojs.ikippgribali.ac.id/index.php/jpkr/article/view/129 